\title{
Indicadores de ocorrência temática no campo da ciência da informação brasileira: uma perspectiva a partir dos artigos publicados no periódico Ciência da Informação
}

\author{
Caio César Delfino Cunha \\ Bibliotecário do Centro de Tecnologias do Gás e Energias Renováveis - CTGÁS/RN \\ Graduado em Biblioteconomia pela Universidade Federal do Rio Grande do Norte \\ E-mail:mr.caiocunha@gmail.com
}

\begin{abstract}
RESUMO:
Trata da ocorrência temática no campo de Ciência da Informação $(\mathrm{Cl})$ no Brasil. Tem como objetivo geral, analisar a produção científica em $\mathrm{Cl}$, através dos artigos publicados na revista Ciência da Informação. Aborda os temas comunicação e conhecimento científico indicando as mudanças paradigmáticas no processo de comunicação científica. Apresenta um breve histórico acerca da Ciência da Informação, bem como seus paradigmas. Utiliza abordagem metodológica quantitativa e qualitativa, utilizando as técnicas de análise da informação e representação temática. Constata a recorrência elevada de pesquisas relacionadas à representação e organização da informação; necessidades e uso da informação; tecnologias, sistemas e redes de informação; formação do profissional da informação; teoria da Ciência da Informação; e métricas da informação. Sugere, através dos resultados, a manutenção de estudos como o da natureza desta pesquisa para a compreensão do cenário e das perspectivas da $\mathrm{Cl}$ no contexto brasileiro, bem como, estudos que tragam melhor compreensão sobre a recorrência temática.
\end{abstract}

Palavras-chave: Ciência da Informação. Produção Científica. Ocorrência temática. Revista Ciência da Informação.

\begin{abstract}
:
Addresses on the theme occurring in the field of Information Science (IS) in Brazil. It has the general objective to analyze the scientific production in Information Science through the articles published in Magazine Information Science. Addresses the communication and scientific knowledge themes indicating the paradigmatic changes in the communication process. Presents a brief history about the information science and its paradigms. Used as methodological approach, quantitative and qualitative research, using analysis of information and thematic representation techniques. Notes the high recurrence of research related to the representation and organization of information; needs and use of information; technologies, systems and networks; professional training information; Theory of Information Science; and metric information. Suggested, by the results, the studies maintenance such as the nature of this research to the understanding of the scenario and the perspectives of IS in the Brazilian context, as well as studies that bring better understanding of the recurring theme.
\end{abstract}

Keywords: Information Science. Scientific production. Thematic occurrence. Magazine Information Science. 


\section{INTRODUÇÃO}

No Brasil, as práticas profissionais e os trabalhos de pesquisa em Ciência da Informação $(\mathrm{Cl})$ foram introduzidos junto às atividades promovidas pelo Instituto Brasileiro de Bibliografia e Documentação, hoje conhecido como Instituto Brasileiro de Informação em Ciência e Tecnologia (IBICT), que, em meados da década de 1970, criou o primeiro Programa de Pós-Graduação em Ciência da Informação no contexto brasileiro.

Desde 1972, vem sendo editada a revista Ciência da Informação, própria do IBICT, que se configurou como um marco histórico na legitimação dessa ciência no país. Caracterizada como representativa publicação no cenário mundial da pesquisa em Ciência da Informação, essa revista nos fornece o insumo básico para a extração dos dados desta pesquisa.

De forma geral, este estudo propõe-se a analisar a produção científica no campo brasileiro da Ciência da Informação por meio dos artigos nela publicados, buscando, especificamente, traçar um perfil histórico da produção científica no campo da $\mathrm{Cl}$; observar a temática de cada artigo publicado na revista Ciência da Informação; oferecer um panorama do campo da $\mathrm{Cl}$ no Brasil.

Desde sua origem, no pós-Segunda Guerra, durante o que podemos denominar como explosão da informação, a Ciência da Informação surge no intuito de inclinar-se a resolver a problemática da criação, organização, armazenagem e transmissão da informação em um contexto no qual havia volumes de informação, os quais, como organismos vivos, cresciam de forma exponencial. Essa ciência é resultado da fusão de conceitos, técnicas e metodologias comuns a várias áreas do conhecimento, cujos cientistas propuseram-se à resolução dessa problemática social.

A gênese conceitual dessa ciência se deu de forma igualitária mundialmente, possuindo sua variabilidade evolutiva dos estudos no que tange aos contextos políticosociais e históricos de cada lugar. Dessa forma, este estudo apresenta o mapeamento das temáticas abordadas no campo da Ciência da Informação em torno do cenário brasileiro.

2 COMUNICAÇÃO E PRODUÇÃO DO CONHECIMENTO CIENTÍFICO 
O fenômeno da comunicação científica não é novidade. Comunicar a ciência é um ato praticado desde a Antiguidade com a formação de colegiados para debates de ideias filosóficas expostas na Grécia Antiga, sob a denominação de Academia (MEADOWS, 1999; CÔRTES, 2006). Um modelo em rede que perdura até a contemporaneidade por meio de canais de comunicação formais e informais, intercambiando informação entre os seus principais atores, os cientistas, com vistas ao progresso científico.

A comunicação científica tem por finalidade disseminar os resultados de pesquisas desenvolvidas pela comunidade científica. Nesse processo, a forma como é transmitida a informação varia de acordo com o veículo, a natureza da informação e o público-alvo. A maneira como a informação é veiculada nos dias de hoje pouco tem a ver com os moldes de dois séculos atrás. Esse efeito decorre das transformações tecno-científicas que ocorreram desde então, assim como os suportes midiáticos tem se transformado e auxiliado a transmissão da informação (MEADOWS, 1999).

Podemos observar esse fenômeno quando nos reportamos ao processo de comunicação por meios informais. A formação e a atuação dos colégios invisíveis, que outrora eram realizados através do envio de correspondência por meio do sistema postal, posteriormente, foram otimizadas com o surgimento da telemática, agilizando seus processos de comunicação com o uso, por exemplo, de webmail e listas de discussão na Internet.

Côrtes (2006) aponta para a mudança de paradigmas mediante o contexto dinâmico dos modelos de comunicação científica. No que se refere a isso, temos como principal agente das revoluções a alteração de como eram transmitidas as informações cientificas no que tange aos suportes e materiais empregados em seu fabrico.

A comunicação oral é até hoje praticada, salvo as mudanças que esse modelo passou devido à incorporação de tecnologias midiáticas, como ressalta Meadows (1999). A promoção de conferências como uma maneira de suscitar o debate científico ainda é comum. Esse modelo de comunicação científica não foi saturado, mas passou a coexistir com outros modelos posteriores.

Outra forma muito comum de comunicação entre os cientistas tinha como veículo as cartas, que devido às distorções envolvidas no processo de transmissão das mensagens, bem como as dificuldades na averiguação da veracidade dos 
experimentos e resultados apontou para um novo modelo de comunicação. Com a franca expansão do uso da prensa tipográfica e do papel, o livro passa a se configurar como principal fonte de informação. A matéria impressa para a divulgação das ideias através da comunidade científica da época tornou-se bastante popular.

A revolução tipográfica somada à formalização dos sistemas postais deu início à veiculação de folhas noticiosas, interligando os centros de comércio. A demanda por esse tipo de informação aumentou a ponto de demonstrar que se valer de textos impressos em vez de manuscritos era uma proposta viável pela rapidez com que eram produzidos e por seu baixo custo. Tal modelo de comunicação serviu de referência para o jornal como o conhecemos hoje, bem como para o surgimento dos periódicos científicos.

Weitzel (2006) verifica que o periódico científico representou um marco na revolução das estruturas da comunicação científica. Advindo da necessidade da transmissão da informação científica a fim de relatar experiências, esse modelo de comunicação trouxe algumas consequências, como é o caso da institucionalização da ciência, da especialização dos saberes e da automatização do campo científico, alcançando seu ápice no século XX frente aos avanços técnico-científicos, ao aumento da comunidade científica e da disposição de recursos para pesquisa e produção (P\&D), mas é durante a $2^{\text {a }}$ Grande Guerra Mundial que esse fenômeno vem a agravar os efeitos da explosão bibliográfica iniciada através da revolução tipográfica.

Se por um lado o periódico científico foi uma iniciativa mais eficaz que os livros para a comunicação científica, por outro, ele começou a demonstrar falhas, principalmente, quanto ao acesso às publicações, sua dependência de recursos financeiros e aumento expressivo do número de títulos que surgiram.

A mudança de paradigma na comunicação científica por veículos impressos se dá não somente pela exaustão proporcionada pela publicação do número de periódicos que vêm aumentando exponencialmente, desde a implementação desse modelo de comunicação, mas também da mediação dos fluxos informacionais a partir do surgimento da Internet. Para Weitzel (2006), a ênfase no acesso aberto com o apoio das tecnologias da informação e comunicação vem a inaugurar um novo modelo para essa modalidade de comunicação, o que possivelmente seria a solidificação de um novo paradigma.

A necessidade de comunicar o conhecimento científico parte da informação transmitida nesses processos como insumo básico para a produção científica. No ciclo 
da produção científica, esse elemento, assim como em diversos segmentos da sociedade, é sua matéria-prima e os pesquisadores a força motriz para a existência dele. Assim, com vistas a alçar um patamar elevado às ciências e à inovação tecnológica, soluções são propostas aos problemas identificados pelos sujeitos na sociedade, gerando produtos intelectuais que são publicados como forma de divulgação da ideia concebida e busca da aprovação por pares da comunidade científica.

Le Coadic (2004) se utiliza da alegoria do esquema clássico da economia produção, distribuição e consumo - para explicar o ciclo da produção científica, ou como ele denominaria, o ciclo da informação científica - construção, comunicação e uso. Para o autor, as três fases sucedem uma à outra, fornecendo o subsídio para a etapa seguinte. Nesse sentido, demonstra-se que a comunicação científica como forma de disseminar o conhecimento produzido com vistas a tornar-se referencial para que, em colaboração, a comunidade científica se esforce e promova novas realizações.

\section{PRODUÇÃO CIENTÍFICA NO CAMPO DA CIÊNCIA DA INFORMAÇÃO}

As revoluções científicas e a ampla produção científica, em especial no pósSegunda Guerra, efetivaram a demanda por mecanismos que obtivessem o controle e a organização do volume crescente de informação, que corroborou na famigerada explosão da informação. Eis que surge uma ciência pautada em teorias de diversas áreas do conhecimento que se inclinaram a resolver tal problema, a Ciência da Informação. Esta se ocupou do entendimento das trocas das informações em sistemas humanos e tecnológicos de comunicação, organização, processamento e recuperação da informação, dentre outros processos, que, assim como o camaleônico conceito de informação, evocam uma infinda multiplicidade de enfoques.

\subsection{CIÊNCIA DA INFORMAÇÃO}

Em um momento no qual emergem as dificuldades encaradas pelos cientistas no tocante à informação científica e seu volume crescente, uma questão é levantada 
sobre quais técnicas seriam adequadas para organizar, armazenar e recuperar essa informação para seu uso.

É a partir dessa demanda social que nasce

a disciplina que investiga as propriedades e comportamento da informação, as forças que governam o fluxo da informação e os meios de processamento da informação para otimizar o acesso e uso. Diz respeito a um corpo teórico relacionado a origem, coleta, organização, armazenamento, recuperação, interpretação, transmissão e transformação e utilização da informação (BORKO 1968, p. 3).

Freire (2006) categoriza os estudos acerca do objeto da Ciência da Informação de três formas, a saber: recuperação da informação, abarcando estudos de representação, tecnologias de processamento e serviços de informação; comunicação da informação, envolvendo olhares no que concerne a tecnologias da informação e comunicação, produção e recepção e uso da informação e canais de comunicação; estudos da cognição, com pesquisas no tocante aos métodos de estudos do usuário, aplicação de inteligência artificial e competência digital, que relacionam-se entre si devido à natureza dinâmica do seu objeto.

Para a Ciência da Informação, em sua constituição, foram tomadas por empréstimo definições de diversas áreas do conhecimento para o objeto da ciência em questão, com vistas a melhor delimitar seu campo de atuação na pesquisa e prática profissional.

Borko (1968, p. 3) pondera que a Ciência da Informação "é uma ciência interdisciplinar derivada e relacionada a áreas como matemática, lógica, lingüística, psicologia, informática, pesquisa de operações, das artes visuais, comunicação, biblioteconomia, administração e outras áreas similares." Nesse ponto, Saracevic (1996) defende que a diversidade das relações mantidas entre a Cl e essas várias áreas do conhecimento é atribuída à formação dos atores envolvidos no processo de resolução do problema para a qual essa ciência nasceu, objetivando-se suprir a demanda social.

Apesar de Saracevic (1996) julgar a interdisciplinaridade como pressuposto essencial para a existência da Ciência da Informação, pode-se denotar que a contribuição dessa gama de áreas de conhecimento, ao propor teorias, técnicas e procedimentos, pode ter ocasionado, também, a imprecisão conceitual no ponto de vista do que se trata a Ciência da Informação e a definição de seu objeto. 
Sobre o fenômeno da importação de conceitos, Smith, Tálamo e Kobashi $(2004)^{1}$, observam que

a alta proporção de 'noções emprestadas' é reveladora, a nosso ver, de uma interdisciplinaridade formal, que não reflete uma interdisciplinaridade real mas um 'empréstimo' de termos de outras áreas, sem que haja uma adaptação, ou customização, dos conceitos aos propósitos das área.

As autoras ainda discorrem que

não se identifica, na área, um sistema conceitual elaborado [...] [e, por consequência] [...], o conceito na área participa de uma cadeia aberta de significação, que compromete o trabalho intelectual, substituindo o processo de geração de conhecimento por um esforço de convencimento sobre a existência a importância da Ciência da Informação (SMITH; TÁLAMO; KOBASHI, 2004).

Numa perspectiva histórica, Freire (2006) discorre que durante a II Guerra Mundial as atividades relacionadas à informação científica adquirem destaque. $\mathrm{O}$ autor observa que

neste período, o mundo passava por um momento de grandes conflitos e os chamados países aliados, notadamente os EUA, URSS e Grã-Bretanha, empregaram um grande número de pessoas a trabalhar em processos de coleta, seleção, processamento e disseminação de informação que fossem relevantes para o esforço de ganhar a guerra (FREIRE, 2006, p. 10, grifo do autor).

Da expedição desse esforço durante o conflito, o manancial de informação emanado das atividades científicas suscitou em Vannevar Bush o olhar sobre problemas, publicados em seu artigo As we may think. Bush apontou para a problemática da sistematização da informação científica e tecnológica disponível no pós-guerra, delimitando como entraves a capacitação dos recursos humanos, os instrumentos para sua armazenagem e recuperação e os mecanismos existentes para a organização e controle da famigerada explosão da informação. Diante disso, é possível considerar Vannevar Bush como precursor da Ciência da Informação, cuja data de publicação de seu artigo marca a fundação deste novo campo científico (BARRETO, 2002).

Por sua vez Freire (2006), mesmo considerando a publicação do artigo de Vannevar Bush um marco, denotando a relevância das atividades de informação científica para a sociedade, atribui aos eventos promovidos pelo Georgia Institute of Technology, na década de 1960, o marco constitutivo da Ciência da Informação, tendo

\footnotetext{
1 Documento eletrônico não paginado.
} 
em vista que nesses eventos foi designada a primeira definição do que seria Ciência da Informação.

Contudo, para Figueiredo (1996), a Ciência da Informação tem sua gênese em um período anterior ao da II Guerra Mundial, com suas raízes na Documentação e nos ideais de Paul Otlet. Isso se torna evidente no momento em que a autora afirma que

o seu Tratado de Documentação, culminação de pensamentos de toda uma vida, é, talvez, a primeira sistemática e moderna discussão dos problemas gerais da organização da informação. O termo documentação é um neologismo, criado por Otlet, para designar o que hoje em dia tendemos a chamar de armazenamento e recuperação da informação. De fato, não é exagero declarar-se que o tratado foi um dos primeiros textos de ciência da informação, pois começa com uma longa exposição geral sobre a comunicação da informação examinadas do ponto de vista de várias ciências (FIGUEIREDO, 1996, p. 16).

É cabível afirmar que ambos os contextos vivenciavam uma expansão vertiginosa do conhecimento registrado, diferenciados, apenas, pelo contexto tecnológico. Enquanto a Documentação preocupava-se com a sistematização de documentos com ênfase em seu conteúdo, a Ciência da Informação foca-se na informação e seus processos de transferência em um contexto no qual as emergentes tecnologias da informação já faziam parte.

Smith, Tálamo e Kobashi (2004) apontam para um eixo evolutivo da Ciência da Informação, transpondo a Biblioteconomia e a Documentação para desaguar na Ciência da Informação, conforme é demonstrado na figura seguinte:

Figura 1 - Eixo evolutivo da Ciência da Informação
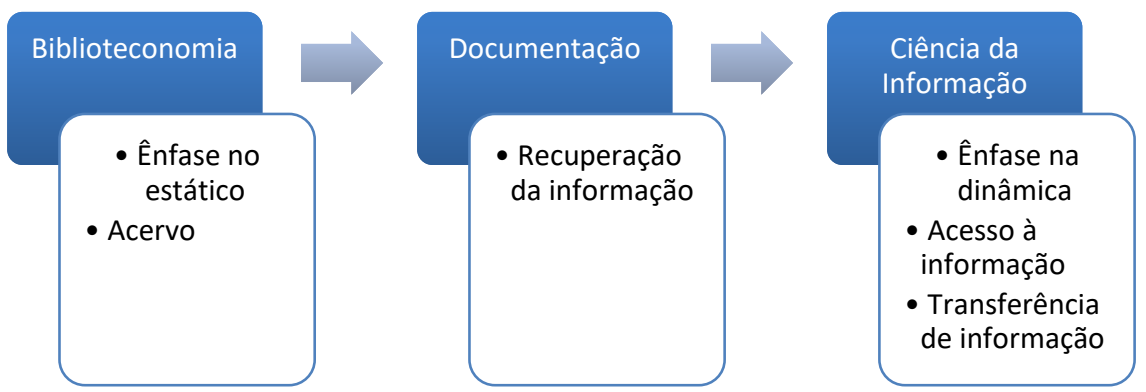

Fonte: Smith, Tálamo e Kobashi (2004, documento eletrônico).

Para as autoras, a figura demonstra o deslocamento do

fulcro do acervo para o acesso à informação, ou seja, uma abordagem estática foi substituída por outra dinâmica e forçosamente social. A Documentação, como ponto de passagem neste esquema, representa uma transformação em relação do paradigma do acervo [...]: à informação estática 
sobrepõe-se se significado social, o acesso (SMITH; TÁLAMO; KOBASHI, 2006) $)^{2}$.

Capurro e Hjorland (2007) identificam o processo de surgimento da Ciência da informação transcorrendo eventos ocorridos no Reino Unido e EUA, como exemplo, a adoção do termo bureau de informação, em vez de balcão de referência, e sua relação com a biblioteca especializada, concluindo que os bibliotecários especializados foram os primeiros documentalistas e estes os primeiros cientistas da informação.

No foco do campo da atuação profissional, Capurro e Hjorland (2007) observam uma mudança. A informação passa a ser objeto e isso tem suas possíveis causas nos seguintes pontos: "[1] um crescente interesse em aplicações computacionais (ou tecnologias da informação); e [2] uma influência teórica indireta da informação da teoria da informação e o paradigma do processamento de da informação nas ciências cognitivas" (HJORLAND, 2000 apud CAPURRO; HJORLAND, 2007, p. 178).

A mudança paradigmática é um aspecto epistemológico da Ciência da Informação que não pode ser esquecida. Capurro $(2003)^{3}$ observa que "a ciência da informação nasce [...] com um paradigma físico, questionado por um enfoque cognitivo idealista e individualista, sendo este por sua vez substituído por um paradigma social ou [...] por uma 'epistemologia social', mas agora de corte tecnológico digital".

Observando as etapas do ciclo de informação, Le Coadic (2004), também, propõe a existência de quatro - novos - paradigmas para a Ciência da Informação, a saber:

a) o paradigma do trabalho coletivo: com a inserção da microinformática como mediadora nos processos de comunicação entre cientistas, tornou-se comum a formação de colégios invisíveis através da rede mundial de computadores. Essa relação de pesquisa pode ocorrer das seguintes formas:

a. em dupla: ocorre a troca de informação entre dois indivíduos;

b. em grupo ou colegiado: intercâmbio de informação por grupos de pesquisadores geograficamente dispersos;

c. em fluxo: troca de informação entre vários indivíduos geograficamente dispersos por meio de um processo preestabelecido.

b) o paradigma do fluxo: a tecnologia da informação tornou dinâmico o processo de criação e disseminação da informação, bem como permitiu

\footnotetext{
2 Documento eletrônico não paginado.

${ }^{3}$ Documento eletrônico não paginado.
} 
a expansão dos tipos de fontes e atribuiu maior agilidade à veiculação da informação;

c) o paradigma do uso: os processos começam a centrar-se no usuário, isto é, tende-se a perder o foco na perspectiva tecnicista para enfatizar uma perspectiva humanística;

d) o paradigma do elétron: Le Coadic ${ }^{4}$ não demonstra clareza ao que se reporta a este, contudo, parece representar os avanços tecnológicos rumo à miniaturização das tecnologias da informação, implicando a criação de novos suportes para informação e uma renovação no fluxo da produção e veiculação de registros do conhecimento.

A história de um campo científico é intrínseca aos avanços e descobertas vivenciados e proporcionados pelos seus atores. Nessa perspectiva, cabe-nos observar que "a evolução da $\mathrm{Cl}$ nos vários países ou regiões acompanhou diferentes acontecimentos ou prioridades distintas, mas a justificativa e os conceitos básicos são os mesmos globalmente. O despertar da $\mathrm{Cl}$ foi o mesmo em todo o mundo" (SARACEVIC, 1996, p. 43).

\subsubsection{Ciência da Informação no Brasil}

Ao darmos enfoque ao campo da Ciência da Informação no Brasil, torna-se imprescindível retratar a atuação do Instituto Brasileiro de Informação em Ciência e Tecnologia.

Em meados da década de 1950, é fundado o instituto Brasileiro de Biblioteconomia e Documentação (IBBD), evidenciando a relevância nas práticas de informação no país. Sua origem remonta a um período de intervenção da Unesco na qual era solicitada a Fundação Getúlio Vargas, que desenvolvia importantes trabalhos em bibliografia e documentação (FERREIRA,1999)5. O esforço para a criação desse instituto foi liderado por Lydia Sambaquy e "procurava retratar inovações [na área de documentação...], abrindo um leque de expansão para outras áreas de especialização e proporcionando a entrada no mercado de outros profissionais" (ZAHER, 2005) ${ }^{6}$.

Ferreira (1990) identificou como majoritário, para o IBBD, o objetivo de "prover informação científica e tecnológica aos pesquisadores que a solicitassem”. Contudo,

\footnotetext{
${ }^{4}$ Le Coadic (2004, p. 111).

5 Documento eletrônico não paginado.

${ }^{6}$ Documento eletrônico não paginado.
} 
o instituto também foi responsável pela qualificação de profissionais para atuarem na área de documentação, para tanto, findou por oferecer cursos de especialização. Esses cursos tinham como proposta lançar no mercado de trabalho, profissionais para lidar com a informação em diferenciados suportes (ZAHER, 2005).

Mais tarde, durante a década de 1970, em reestruturação, o IBBD passa a denominar-se Instituto Brasileiro em Informação para Ciência e Tecnologia, bem como, com a ascensão da microinformática e sua emergente aplicação nas técnicas de documentação, foi instituído o primeiro programa de pós-graduação em Ciência da Informação no país, graças a uma parceria promovida entre esse instituto e a Universidade Federal do Rio de Janeiro.

Pinheiro e Loureiro (1995) destacam o momento oportuno em que foi instituído o programa de pós-graduação, tanto pela incorporação da informação científica e tecnológica nos planos governamentais com o planejamento do Sistema Nacional de Informação em Ciência e Tecnologia (SNICT) quanto pelas ações decorrentes das atividades da Unesco para a criação do Sistema Mundial de Informação Científica e Tecnológica (Unisist), resvalando na criação dos Sistemas Nacionais de Informação Científica e Tecnológica (Natis).

\subsubsection{Revista Ciência da Informação}

O IBICT foi responsável pela publicação do primeiro periódico portando no título o termo ciência da informação, o que pode ser reconhecido como marco para a institucionalização da atividade de pesquisa na área. Entretanto, faz-se necessário citar que no período referente à sua gênese, a revista Ciência da Informação, no cenário da comunicação científica, dividia espaço com a Revista da Escola de Biblioteconomia, da UFMG, hoje conhecida como Perspectivas em Ciência da Informação. Essa consideração é necessária pelo fato de a Biblioteconomia dedicarse a práticas consonantes às da Ciência da Informação, conotando a similaridade da temática dos estudos publicados em ambos os periódicos.

A revista Ciência da Informação teve seu primeiro número publicado no ano de 1972, abarcando seis artigos. Até então, o instituto responsável por sua editoração

- ainda respondendo pela alcunha de Instituto Brasileiro de Bibliografia e Documentação, nesse período - lançava a revista "dois anos depois do início do Mestrado em Ciência da Informação do IBICT, [correspondendo a uma] iniciativa 
pioneira na América Latina e no Ano Internacional do Livro, o que mereceu chamada de capa" (PINHEIRO; BRÄSCHER; BURNIER, 2005, p. 30).

Em se tratando dos periódicos da área de Ciência da Informação no Brasil, a referida revista se consolidou no cenário nacional, tendo em vista as quatro décadas de sua atividade.

Para Zaher $(2005)^{7}$, em um cenário de transformações e avanços das práticas em documentação, principalmente no que tange à difusão da automação de acervos, a revista Ciência da Informação "foi lançada com a finalidade de difundir essas novas ideias no quotidiano e nas preocupações dos bibliotecários brasileiros”.

Essa revista, hoje, configura-se como "uma publicação quadrimestral de trabalhos inéditos relacionados com a ciência da informação ou que apresentem resultados de estudos e pesquisas sobre as atividades do setor de informação em ciência e tecnologia" (SOBRE...) $)^{8}$.

Em sua política editorial, são descritos aspectos do processo de avaliação dos artigos submetidos. A primeira delas é a avaliação feita por dois ou mais especialistas, que possuem propriedade acerca do assunto do artigo avaliado, em que o número de especialistas convocados dependerá da necessidade imposta pela temática. Durante o processo de avaliação, é praticado o blind review (ou avaliação cega por pares), na qual a autoria dos artigos não é revelada de forma a garantir a impessoalidade e qualquer influência para sua aprovação. Após isso, os artigos são encaminhados para um comitê, o Editorial, para a seleção dos artigos que irão compor o número da revista.

É interessante destacar enquanto característica da revista Ciência da Informação seu caráter de acesso livre, garantindo o acesso público e gratuito, o que visa contribuir para maior divulgação do que é produzido no campo brasileiro da $\mathrm{Cl}$ e, ainda, colaborar com o ciclo de produção do conhecimento científico. Outra característica da referida revista é a indexação dela por vinte e três unidades, que derivam entre portais, bases de dados, bibliotecas virtuais, diretórios e repositórios distribuídos em sete países.

Pinheiro, Bräscher, Burnier (2005, p. 36), ao se reportarem à temática abordada no conteúdo do periódico em pauta, afirmam que

desde o seu início, a temática da revista Ciência da Informação reflete bem as questões da área e, de um modo geral, as pesquisas desenvolvidas no Brasil estão direcionadas aos mesmos temas estudados no exterior,

\footnotetext{
7 Documento eletrônico não paginado.

${ }^{8}$ Documento eletrônico não paginado.
} 
aparecendo diferenças de ênfase, por circunstâncias históricas, sociais e científicas nacionais.

É nessa perspectiva que a revista Ciência da Informação foi escolhida como objeto desta pesquisa para buscar retratar o cenário da produção científica no campo da Ciência da Informação no Brasil.

\section{METODOLOGIA}

Para esta pesquisa, foi delimitado como universo a revista Ciência da Informação, que, inserida no contexto brasileiro, trata-se de periódico de vanguarda. Tem-se em perspectiva que esta revista nos fornecerá o panorama que é pretendido por este trabalho, isto é, ela pode nos oferecer o retrato do que compõe o cenário da produção científica no campo da Ciência da Informação. Além disso, acredita-se que esse periódico seja um dos principais veículos da comunicação científica no Brasil no campo da $\mathrm{Cl}$, servindo de referência para os pesquisadores da área se inteirarem das temáticas de pesquisa e inovação, findando por lançar tendências no que é produzido em termos de conhecimento nessa área no país.

A partir de uma pesquisa realizada por Pinheiro, Bräscher, Burnier (2005), com a colaboração de Marisa Bräscher e Sonia Burnier, que objetivou delinear o caráter evolutivo da revista Ciência da Informação, em específico, "o conteúdo dos artigos publicados no periódico, identificando temas ou disciplinas abordados, como reflexo da evolução da ciência da informação no Brasil" (PINHEIRO; BRÄSCHER; BURNIER, 2005, p. 24), tem-se o subsídio para a estruturação do método de coleta dos dados.

Por essas autoras, foram avaliados os artigos publicados entre o período de 1972 e o primeiro número do ano de 2004. Os artigos publicados após esse período foram analisados nesta pesquisa, correspondendo ao período a partir do segundo número de 2004 ao último número de 2011.

Esta pesquisa pode ser classificada como quantitativa e qualitativa, uma vez que preocupa-se em quantificar estatisticamente dados extraídos de um universo literário e científico e justificá-los em determinado contexto. Nesse sentido, pode-se afirmar que este estudo centra-se no âmbito da bibliometria.

As referidas autoras, ao realizarem o levantamento, estabeleceram categorias mediante a frequência dos temas abordados. Sendo assim, essas categorias foram 
aproveitadas ao máximo, buscando evitar redundâncias em comparação ao trabalho desenvolvido anteriormente.

Tanto a presente pesquisa quanto a das autoras fazem da prática profissional bibliotecária sua metodologia de coleta, uma vez que nos apropriamos das técnicas de análise da informação e representação temática - em especial, da indexação - para representar os artigos. Para tanto, foram observados os títulos, os resumos e as seções dos artigos, a fim de encontrar pistas de como melhor identificar a temática da matéria documental.

Cabe-nos aqui destacar que mesmo sendo hercúleo o esforço de representar a informação, tendo em vista o alinhamento com a pesquisa de Pinheiro, Bräscher, Burnier (2005), é sábio afirmar que o produto da representação pode conter incoerências entre as duas pesquisas. Isso decorre do fato de que os mapas conceituais e relações mentais são diferentes entre ambas as equipes.

\section{RESULTADOS}

Buscando delinear a trajetória da revista Ciência da Informação do Instituto Brasileiro de Informação em Ciência e Tecnologia (IBICT), Pinheiro, Bräscher e Burnier (2005) analisaram, dentre outros aspectos, como se deu a evolução da abordagem temática no campo da Ciência da Informação por meio desse periódico. $O$ resultado desse levantamento pode ser conferido na Tabela 1, a qual nos servirá para traçar um perfil da produção científica nessa área, levando em consideração a premissa, já mencionada, de seu caráter vanguardista legitimado pela comunidade científica.

Tabela 1 - Frequência de temas de artigos da Ciência da Informação distribuídos por décadas

\begin{tabular}{|c|c|c|c|c|c|c|c|c|c|c|}
\hline Temas & \multicolumn{2}{|c|}{$\begin{array}{c}1972-1979 \\
(\%)\end{array}$} & \multicolumn{2}{|c|}{$\begin{array}{c}1980-1989 \\
(\%)\end{array}$} & \multicolumn{2}{|c|}{$\begin{array}{c}1990-1999 \\
(\%)\end{array}$} & \multicolumn{2}{|c|}{$\begin{array}{c}2000-2004 \\
(\%)\end{array}$} & \multicolumn{2}{|c|}{ Total (\%) } \\
\hline 1. Teoria da ciência da informação & 4 & 4,65 & 8 & 7,33 & 23 & 9,2 & 14 & 9,45 & 49 & 8,26 \\
\hline 2. Bibliometria & 18 & 20,93 & 11 & 10,09 & 14 & 5,6 & 5 & 3,37 & 48 & 8,09 \\
\hline 3. Representação da informação & 8 & 9,3 & 9 & 8,25 & 15 & 6 & 14 & 9,45 & 46 & 7,75 \\
\hline 4. Políticas de informação & 3 & 3,48 & 11 & 10,09 & 12 & 4,8 & 17 & 11,48 & 43 & 7,25 \\
\hline 5.Necessidades e usos de informação & 6 & 6,97 & 9 & 8,25 & 16 & 6,4 & 11 & 7,43 & 42 & 7,08 \\
\hline 6. Gestão da informação & 2 & 2,32 & 7 & 6,42 & 25 & 10 & 7 & 4,72 & 41 & 6,91 \\
\hline 7. Comunicação científica & 7 & 8,13 & 10 & 9,17 & 12 & 4,8 & 10 & 6,75 & 39 & 6,57 \\
\hline
\end{tabular}




\begin{tabular}{|c|c|c|c|c|c|c|c|c|c|c|}
\hline 8. Tecnologias da informação & & & 1 & 0,91 & 18 & 7,2 & 18 & 12,16 & 37 & 6,23 \\
\hline 9. Formação e aspectos profissionais & 6 & 6,97 & 9 & 8,25 & 15 & 6 & 4 & 2,7 & 34 & 5,73 \\
\hline 10. Sistemas e redes de informação & 6 & 6,67 & 6 & 5,5 & 17 & 6,8 & 3 & 2,02 & 32 & 5,39 \\
\hline 11. Disseminação da informação & 4 & 4,65 & 7 & 6,42 & 16 & 6,4 & 4 & 2,7 & 31 & 5,22 \\
\hline $\begin{array}{l}\text { 12. Sistemas de recuperação da } \\
\text { informação }\end{array}$ & 4 & 4,65 & 2 & 1,83 & 6 & 2,4 & 9 & 6,08 & 21 & 3,54 \\
\hline 13. Bibliotecas virtuais/digitais & & & & & 6 & 2,4 & 11 & 7,43 & 17 & 2,66 \\
\hline 14. Inteligência competitiva & & & & & 8 & 3,2 & 5 & 3,37 & 13 & 2,19 \\
\hline 15. Política de Ciência e Tecnologia & & & 3 & 2,75 & 7 & 2,8 & 2 & 1,35 & 12 & 2,02 \\
\hline 16. Bases de dados & 3 & 3,48 & 4 & 3,66 & 2 & 0,8 & 2 & 1,35 & 11 & 1,85 \\
\hline $\begin{array}{l}\text { 17. Organização e processamento da } \\
\text { informação }\end{array}$ & 6 & 6,97 & 1 & 0,91 & 1 & 0,4 & 2 & 1,35 & 10 & 1,68 \\
\hline 18. Economia da informação & & & 2 & 1,83 & 5 & 2 & 2 & 1,35 & 9 & 1,51 \\
\hline 19. Biblioteconomia/Bibliotecas/Livros & 2 & 2,32 & 3 & 2,75 & & & 2 & 1,35 & 7 & 1,18 \\
\hline 20. Arquivologia & & & & & 6 & 2,4 & & & 6 & 1,01 \\
\hline $\begin{array}{l}\text { 21. Processamento automático da } \\
\text { linguagem }\end{array}$ & 1 & 1,16 & 1 & 0,91 & 4 & 1,6 & & & 6 & 1,01 \\
\hline 22. Automação de bibliotecas & 2 & 2,32 & 1 & 0,91 & 2 & 0,8 & 1 & 0,67 & 6 & 1,01 \\
\hline 23. Divulgação científica & & & 1 & 0,91 & 2 & 0,8 & 1 & 0,67 & 4 & 0,67 \\
\hline 24. Ciência e Tecnologia & & & & & 3 & 1,2 & & & 3 & 0,5 \\
\hline 25. Gestão do conhecimento & & & & & & & 3 & 2,02 & 3 & 0,5 \\
\hline 26. Política editorial & 2 & 2,32 & 1 & 0,91 & & & & & 3 & 0,5 \\
\hline 27. Sistemas especialistas & & & & & 2 & 0,8 & & & 2 & 0,33 \\
\hline 28. Comunicação social & & & & & 2 & 0,8 & & & 2 & 0,33 \\
\hline 29. Imprensa & & & & & 2 & 0,8 & & & 2 & 0,33 \\
\hline 30. Linguística & & & & & 2 & 0,8 & & & 2 & 0,33 \\
\hline 31. Tecnologias & & & & & 2 & 0,8 & & & 2 & 0,33 \\
\hline $\begin{array}{l}\text { Temas com frequência } 1 \text { no somatório } \\
\text { geral }\end{array}$ & 2 & 2,32 & 2 & 1,83 & 5 & 2 & 1 & 0,67 & 10 & 1,68 \\
\hline Total & 86 & 100 & 109 & 100 & 250 & 100 & 148 & 100 & 593 & 100 \\
\hline
\end{tabular}

Fonte: Pinheiro, Bräscher e Burnier (2005, p. 36).

Durante a primeira década de existência da revista, é constatada a alta frequência de artigos publicados sobre "Bibliometria" (18). Isso decorre da inserção da disciplina no Brasil, graças à presença de consultores convidados pelo recém-fundado curso de mestrado em $\mathrm{Cl}$ do IBICT/UFRJ, fato observado por autores como Robredo (2003) e Pinheiro (1995).

Nessa mesma década, em 1970, é expressiva a produção no que concerne às temáticas "Representação da informação" (8), "Comunicação científica" (7), "Formação e aspectos profissionais" (6), "Necessidades e usos de informação" (6), "Organização e processamento da informação" (6), "Sistemas e redes de informação" 
(6). Podemos, a partir disso, inferir que havia certa recorrência em tratar de questões pertinentes à cadeia de processos referentes ao ciclo da informação, em especial, a informação científica - objeto ao qual a Ciência da Informação a priori propôs-se a tratar enfaticamente. Conforme Pinheiro, Bräscher e Burnier (2005, p. 37), também "chama atenção, já nessa década, a identificação de assuntos de ponta" representados pela perspectiva de "Processamento automático da linguagem" (1), cuja abordagem somente obterá maior fôlego na década de 1990, possivelmente derivando dos maiores avanços tecnológicos do período.

Ao analisar os temas dos artigos publicados na década de 1980, é verificada certa continuidade das temáticas abordas na década anterior, valendo destacar a aparecimento dos temas sobre "Política de Ciência e Tecnologia" (3) e "Economia da Informação" (2), bem como o de um número mais expressivo de artigos acerca de "Política da Informação" (11). O realce dessas temáticas é concomitante à institucionalização dos sistemas de informação científica e tecnológica no país por intervenções da UNESCO, apontando para a produção nesses temas uma consequência do contexto histórico-político.

Já a década de 1990 é marcada por grandes transformações de ordem tecnológicas e sociais, sendo o expoente dessas revoluções a Internet. Tal evento torna emergente a discussão das temáticas das "Bibliotecas virtuais/digitais" (6), assim como demonstra uma expansão na frequência dos artigos acerca de "Tecnologia da informação" (18) e "Sistemas e redes de informação" (17). Nesse contexto de revoluções tecnológicas, as novas tecnologias da informação passam a se configurar como potenciais ferramentas na gestão de processos nas organizações, não excetuando aquelas do setor da produção da informação. A partir disso, é possível afirmar que, como consequência, a temática "Gestão da informação" (25) atinge seu ápice nessa década, possivelmente, corroborando o surgimento da "Inteligência competitiva" (8), ao destacar a informação e o conhecimento como elementos subsidiários para a vantagem em mercados.

Outro aspecto enfatizado durante a década de 1990 é a temática "Teoria da ciência da informação" (23). Em síntese do que foi dito por Robredo (2003), essa década foi marcada pelo movimento teórico na busca por relações entre Ciência da Informação e Biblioteconomia, ou seja, da mesma maneira que aconteceu com a Biblioteconomia, pode ter ocorrido a relação da $\mathrm{Cl}$ com outras áreas do conhecimento como forma de delimitar melhor seu campo de atuação, diversas teorias a respeito do 
seu objeto (a informação) e delimitação de sua prática profissional podem ter ocorrido ao mesmo tempo, o que explicaria o aumento considerável de artigos que tratam do tema nesse período.

Nos números publicados no limiar do século XXI, assim como na transição da década de 1980 para a de 1990, são observadas poucas mudanças nas tendências na recorrência das temáticas, havendo apenas alterações relativas nos números de incidência temática, o que, possivelmente, provém do número de artigos aprovados para publicação na revista. Contudo, vale ressaltar a emergência do tema "Bibliotecas virtuais/digitais" (11). A exploração dessa temática desenrola-se, muito provavelmente, pela expansão do número de bibliotecas desse tipo e dos movimentos para sua conceituação e de estudos dos modelos descritivos e representativos da informação nelas depositados, além disso, soma-se a relevância adquirida pela inciativa dos arquivos abertos, que culminou na referida expansão, tendo em vista que sua estrutura foi avaliada como elemento viável para a comunicação da informação, bastando nos reportarmos ao exemplo do esforço do IBICT para a implantação de uma rede de bibliotecas digitais de teses e dissertações.

O estudo desenvolvido por Pinheiro, Bräscher e Burnier (2005) encerra-se no primeiro número da revista Ciência da Informação, publicada no ano de 2004. Esta pesquisa dá prosseguimento à análise feita, tomando como ponto de partida o segundo número do volume 33 e encerrando no terceiro número do volume 40 , publicado no terceiro quadrimestre de 2011. Foi indexado um somatório de 199 artigos, conforme podemos tomar conhecimento da evolução, no que tange ao número de artigos publicados, observando a Tabela 2.

Tabela 2 - Número total de artigos publicados no período de

\begin{tabular}{cccc}
\multicolumn{4}{c}{$\mathbf{2 0 0 4}$ a 2011 } \\
\hline Ano & Volume & Número & Total de artigos \\
2004 & 33 & 2 & 18 \\
2004 & 33 & 3 & 8 \\
2005 & 34 & 1 & 10 \\
2005 & 34 & 2 & 9 \\
2005 & 34 & 3 & 2 \\
2006 & 35 & 1 & 9 \\
2006 & 35 & 2 & 11 \\
2006 & 35 & 3 & 18 \\
2007 & 36 & 1 & 13 \\
2007 & 36 & 2 & 9 \\
2007 & 36 & 3 & 7
\end{tabular}




\begin{tabular}{cccc}
2008 & 37 & 1 & 9 \\
2008 & 37 & 2 & 8 \\
2008 & 37 & 3 & 6 \\
2009 & 38 & 1 & 9 \\
2009 & 38 & 2 & 6 \\
2009 & 38 & 3 & 10 \\
2010 & 39 & 1 & 5 \\
2010 & 39 & 2 & 6 \\
2010 & 39 & 3 & 5 \\
2011 & 40 & 1 & 4 \\
2011 & 40 & 2 & 10 \\
2011 & 40 & 3 & 7 \\
\hline
\end{tabular}

Por parte desta pesquisa, não se propôs uma tabela que analisasse a recorrência de artigos junto aos resultados coletados por Pinheiro e suas colaboradoras. Justifica-se essa tomada de decisão perante o que já foi descrito na seção anterior quanto às questões de relações conceituais que cada indexador envolvido faz, enquanto desenvolve o processo de representação temática dos artigos. Tem-se isso como medida de evitar qualquer equívoco ao analisar os dados referentes à última década, que compreenderia o período entre 2000 e 2009.

Tabela 3 - Frequência de temas de artigos da Ciência da Informação do período 2004-2011

Temas

1. Teoria da ciência da informação

$2312 \%$

2. Bibliometria

3. Representação da informação

4. Políticas de informação

5. Necessidades e usos de informação

6. Gestão da informação

7. Comunicação científica

8. Tecnologias da informação

9. Formação e aspectos profissionais

10. Sistemas e redes de informação

11. Disseminação da informação

12. Sistemas de recuperação da informação

13. Bibliotecas virtuais/digitais

14. Inteligência competitiva

15. Política de Ciência e Tecnologia

16. Bases de dados

17. Organização e processamento da informação

18. Economia da informação 


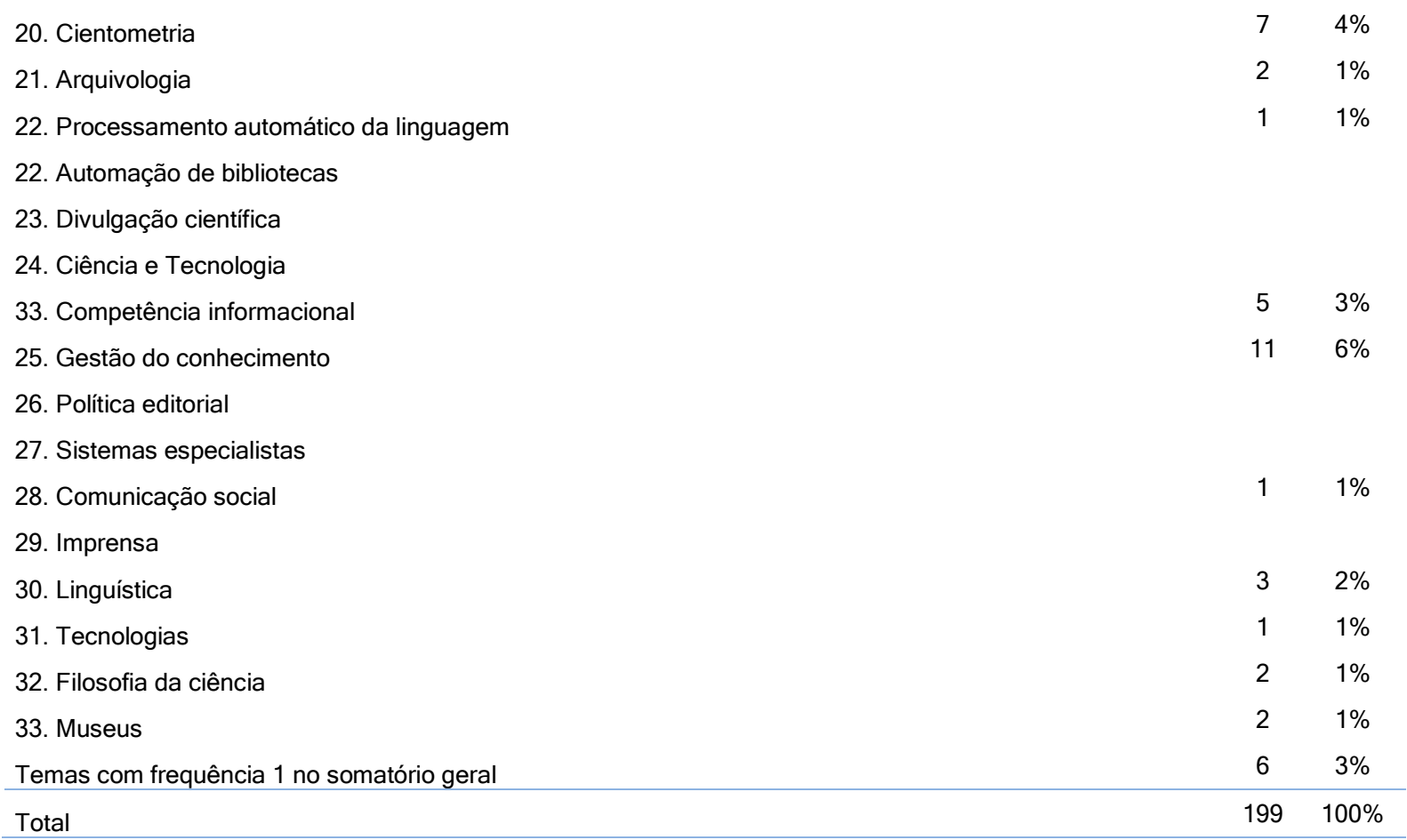

Em comparação entre a Tabela 1 e a Tabela 3, é possível perceber que a gradação no número de artigos a respeito de determinados temas segue a tendência de anos anteriores, deixando clara a predominância de estudos que tratem de "Teoria da ciência da informação", "Bibliometria", "Representação da informação", "Políticas de informação", "Necessidades e usos de informação", "Gestão da informação", "Comunicação científica", "Tecnologias da informação", "Organização e processamento da informação", "Sistemas e redes de informação", "Disseminação da informação" e "Formação e aspectos profissionais", cuja sequência de citação, aqui, não representa o ordenamento de acordo com seu número de ocorrências.

Dentre as áreas temáticas, anteriormente existentes, que ganharam expressividade, podemos citar a "Gestão do Conhecimento", que se apresentou três vezes no período de 2000-2004 na análise de Pinheiro, Bräscher e Burnier (2005), sendo que, nesta pesquisa, foi constatada uma frequência de onze artigos publicados durante o período que vai do segundo quadrimestre de 2004 ao término do ano de 2011.

Nesse entremeio, torna-se evidente o aparecimento da "Competência informacional", com a recorrência de cinco artigos. A temática surge num contexto em que é emergente a questão do uso eficiente de fontes de informação ou, até mesmo, como indivíduos capazes de recuperar a informação e processá-la de forma a garantir direitos, consolidar sua cidadania, e ainda, incluir-se socialmente. O exposto incita a 
indagação do motivo pelo qual estudos dessa natureza não foram inseridos em estudos de necessidade e usos da informação. Nesse sentido, vale ressaltar que muito além do mapeamento das causas do surgimento da disciplina, foi estabelecida sua relevância para compor o quadro em nova categoria, pela sua relação interdisciplinar estabelecida com a Educação, isto é, uma característica inexorável da Ciência da Informação junto à recorrência acima de dois dentre os artigos publicados na revista.

As Métricas em informação também têm se tornado evidentes no que é publicado pela revista. Além da "Bibliometria", a "Cientometria" foi inserida como categoria por apresentar um número de sete artigos na análise feita por esta pesquisa. Outras modalidades de métricas em informação que aparecem por meio deste estudo são a "Webometria" e "Infometria", apresentadas na ocorrência de um artigo publicado para cada tema, como vemos na Tabela 4.

Tabela 4 - Recorrência dos temas do artigo

\begin{tabular}{|c|c|}
\hline Temas & Ocorrência \\
\hline Arquivologia & 2 \\
\hline Bases de dados & 1 \\
\hline Bibliometria & 7 \\
\hline Bibliotecas virtuais/digitais & 5 \\
\hline Biblioteconomia, bibliotecas e livros & 8 \\
\hline Cientometria & 7 \\
\hline Competêcia digital & 1 \\
\hline Competência informacional & 5 \\
\hline Comunicação científica & 22 \\
\hline Comunicação social & 1 \\
\hline Disseminação da informação & 5 \\
\hline Economia da informação & 3 \\
\hline Filosofia da ciência & 2 \\
\hline Formação e aspectos profissionais & 5 \\
\hline Gestão da informação & 12 \\
\hline Gestão do conhecimento & 11 \\
\hline Infometria & 1 \\
\hline Inteligência competitiva & 8 \\
\hline Linguística & 3 \\
\hline Museus & 2 \\
\hline Necessidades e usos de informação & 14 \\
\hline Organização e processamento da informação & 11 \\
\hline Política de Ciência e Tecnologia & 1 \\
\hline Políticas de informação & 8 \\
\hline Processamento automático da linguagem & 1 \\
\hline Propriedade intelectual & 1 \\
\hline Representação da informação & 10 \\
\hline
\end{tabular}




\begin{tabular}{lc} 
Segurança da informação & 1 \\
Serviços de informação & 1 \\
Sistemas de recuperação da informação & 4 \\
Sistemas e redes de informação & 5 \\
Tecnologias & 1 \\
Tecnologias da informação & 6 \\
Teoria da ciência da informação & 23 \\
Webometria & 1 \\
\hline Total & 199
\end{tabular}

A Tabela 4 apresenta a ocorrência de forma detalhada da abrangência temática dos artigos. Através dela, temos a oportunidade de verificar quais temas foram omitidos por sua incidência igual a um, não sendo contemplados com inserção em uma categoria preexistente.

\section{CONSIDERAÇÕES FINAIS}

À guisa de conclusões, o ato de informar se configura como a maneira de assegurar o andamento da multiplicidade dos trabalhos e ideias humanas, uma vez que essa atividade subsidia o processo para a formação do conhecimento, da mesma forma que a informação, podendo ser visto como agente modificador da realidade.

$\mathrm{Na}$ comunicação científica, o ato de comunicar o conhecimento produzido torna-se de fundamental importância para alimentar o fluxo da produção científica, com o qual fizemos analogia ao fluxo da informação, que compreende etapas de construção, comunicação e uso, sucedendo-se uma a outra, o que doa a esse fluxo um caráter cíclico.

No contexto do pós-Segunda Guerra, devido ao fato de os países aliados terem expedido o esforço de contribuir para esse ciclo de produção do conhecimento científico com vistas a garantir vantagem durante o período de conflito, volumes vertiginosos de informação tinham sido produzidos e implicavam problemas para seu uso eficiente pela comunidade científica. Diante disso, a própria comunidade científica inclinou-se à busca da solução do controle desse evento que ficou conhecido como a explosão da informação, termo cunhado por Vannevar Bush em seu artigo As we may think, publicado em meados da década de 1940.

Desse esforço coletivo de diversas ciências, surgiu uma ciência que buscou afinar-se com o que havia sido proposto pelas expressivas descobertas. Nessa fusão de perspectivas teóricas e metodológicas, nasce a Ciência da Informação, uma ciência 
de caráter interdisciplinar, preocupada com o entendimento dos processos de transferência de conhecimento em sistemas humanos e tecnológicos de comunicação, organização, processamento e recuperação da informação.

Essa ciência evoluiu de variadas formas em diferentes contextos, em diversas regiões do mundo, entretanto, sua gênese e conceituação são as mesmas globalmente. No Brasil, a Ciência da Informação inicia suas atividades junto ao Instituto Brasileiro de Bibliografia e Documentação, que, durante a década de 1970, passa a chamar-se Instituto Brasileiro de Informação em Ciência e Tecnologia, culminando também na criação do Programa de Pós-Graduação em Ciência da Informação, com o objetivo de qualificar profissionais para atuarem na área.

Um marco na institucionalização da Ciência da Informação, no país, foi o lançamento da revista Ciência da Informação, com seu primeiro número publicado em 1972. Legitimado entre os membros pesquisadores da comunidade científica da $\mathrm{Cl}$, no mundo, o referido periódico é reconhecido por retratar o contexto brasileiro da pesquisa no campo da Ciência da Informação, alinhando-se ao que é discutido no exterior, tendo a sua variabilidade devido ao nosso contexto histórico-político e social.

Nesse sentido, buscou-se representar os artigos publicados nessa revista com vistas a mapear o que é discutido no Brasil no que tange ao campo científico da Ciência da Informação. Para tanto, foi realizado o método de coleta de dados, organizando seus resultados inicialmente por décadas, tendo em vista que uma pesquisa anterior havia sido elaborada. Essas décadas envolviam períodos de 1972 a 1979, 1980 a 1989, 2000 a 2004 e, posteriormente, uma nova análise foi feita, abrangendo o período de 2004 a 2010.

A sua primeira divisão corresponde à pesquisa desenvolvida por Lena Vânia Pinheiro e sua colaboradoras, que analisaram e indexaram os artigos referentes às edições da revista Ciência da Informação publicadas desde o primeiro número do Volume 1, de 1972, ao primeiro número do Volume 33, de 2004. Dando prosseguimento, o autor desta pesquisa fez a análise e indexação dos artigos publicados posteriormente na revista, correspondendo ao segundo número do Volume 33, de 2004, ao terceiro número do Volume 39, publicado em 2010.

Por meio deste levantamento, foi constatada grande recorrência de pesquisas que visam aspectos em torno da representação e organização da informação; necessidades e uso da informação; tecnologias, sistemas e redes de informação; formação do profissional da informação; teoria da Ciência da Informação; e métricas 
da informação. Esse aspecto denotou a preocupação dos pesquisadores em aprimorar ou tecer considerações a respeito desses assuntos ou apresentar novas abordagens sobre estudos interdisciplinares para o campo da Ciência da Informação.

Chamou-nos a atenção a ênfase dada às métricas da informação, em especial a bibliometria. Acreditamos que a incidência do grande número de artigos publicados na temática advém de uma tradição da pesquisa sobre o tema, estabelecida durante a fase de consolidação do Programa de Pós-Graduação em Ciência da Informação do IBICT, que contou com a consultoria de pesquisadores do exterior e foi postergada pelos especialistas formados nos cursos de especialização e mestrado da época.

No geral, as Métricas da informação ganharam espaço na publicação, tendo em vista o aparecimento de artigos que tratassem, também, de infometria e webometria, assim como a emergência do tema cientometria no período que corresponde a 2004-2010.

Sendo assim, é observada a importância da manutenção de estudos como o da natureza desta pesquisa para compreendermos o cenário e as perspectivas da Ciência da Informação no contexto brasileiro. Sugerimos, também, o desenvolvimento de um estudo que colabore para a compreensão da origem da recorrência temática da bibliometria, bem como a necessidade do uso desses estudos bibliométricos diante da emergência de temas como cientometria, infometria e webometria.

\section{REFERÊNCIAS}

BARRETO, Aldo de Albuquerque. A condição da informação. São Paulo em Perspectiva, São Paulo, v. 16, n. 3, 2002. Disponível em:

<http://www.scielo.br/pdf/spp/v16n3/13563.pdf>. Acesso em: 23 nov. 2011.

BARRETO, Aldo de Albuquerque. A questão da informação. São Paulo em Perspectiva, São Paulo, v. 8, n. 4, 1994. Disponível em:

<http://aldoibct.bighost.com.br/quest/quest2.pdf>. Acesso em: 23 nov. 2011.

BELKIN, N.J. Anomalous states of knowledge as a basis for information retrieval. Canadian Journal of Information Science, n.5, 1980.

BORKO, H. Information Science: what is it? American Documentation, [S.I.],v. 19, n. 1, jan. 1968.

CAPURRO, Rafael. Epistemologia e ciência da informação. In: ENCONTRO NACIONAL DE PESQUISA EM CIÊNCIA DA INFORMAÇÃO, 5., 2003. Anais... Belo Horizonte: [s.n.], 2003. Disponível em: < http://www.capurro.de/enancib_p.htm>. Acesso em: 23 nov. 2011. 
CAPURRO, Rafael; HJORLAND, Birger. O conceito de informação. Perspect. ciênc. inf., Belo Horizonte, v.12, n.1, jan./abr., 2007. Disponível em:

<http://portaldeperiodicos.eci.ufmg.br/index.php/pci/article/view/54 >. Acesso em: 20 set. 2011.

CÔRTES, Pedro Luís. Considerações sobre a evolução da ciência e da comunicação científica. In: POBLACION, D. A.; WITTER, G. P.; SILVA, J. F. M. Comunicação e produção científica: contexto, indicadores e avaliação. São Paulo: Angellara, 2006.

FERNANDES, Ângela Silva et al. Tecnologia e comunicação. In: SIMEÃO, Elmira; MIRANDA, Antônio (Org.). Informação e tecnologia. Brasília: UnB, 2006.

FERREIRA, José Rincon. Editorial: 25 anos do Programa de Pós-Graduação do IBICT. Ciência da informação, v.24, n.1, 1995. Disponível em: <http://revista.ibict.br/ index.php/ciinf/article/view/569/517>. Acesso em: 23 nov. 2011.

FERREIRA, José Rincon. Editorial: Os 45 anos do IBICT. Ciência da informação, Brasília, v. 28, n. 1, 1999. Disponível em: <http://revista.ibict.br/index.php/ciinf/ article/view/319/284>. Acesso em: 23 nov. 2011.

FIGUEIREDO, Nice. Paul Otlet e o centenário da FID. In: ORGANIZAÇÃO do conhecimento e sistemas de classificação. Brasília: IBICT, 1996.

FONSECA, Maria Odila. Arquivologia e ciência da informação. Rio de Janeiro: FGV, 2005.

FREIRE, Gustavo Henrique. Ciência da informação: temática, histórias e fundamentos. Perspect. ciênc. Inf., Belo Horizonte, v. 11, n. 1, jan./abr. 2006. Disponível em: <http://www.scielo.br/pdf/pci/v11n1/v11n1a02.pdf>. Acesso em: 25 nov. 2011.

LE COADIC, Yves-François. A ciência da informação. Tradução de Maria Yêda F. S. de Filgueiras Gomes. 2. ed. Brasília: Briquet de Lemos, 2004.

MEADOWS, A. J. A comunicação científica. Tradução de Antônio Agenor Briquet de Lemos. Brasília: Briquet de Lemos, 1999.

OLIVEIRA, Djalma de Pinho Rebouças de. Sistemas de informações gerenciais: estratégias, táticas, operacionais. 6. ed. São Paulo: Atlas, 1999.

PINHEIRO, L. V. R. Ciência da Informação: desdobramentos disciplinares, interdisciplinaridade e transdisciplinaridade. In: GONZÁLEZ DE GÓMEZ, Maria Nélida; ORRICO, Evelyn Goyannes Dill (Org.). Políticas de memória e informação: reflexos na organização do conhecimento. Natal: EDUFRN, 2006. Disponível em: <http://ridi.ibict.br/bitstream/123456789/18/1/Pinheirodesdobramentos.pdf>. Acesso em: 23 nov. 2011.

PINHEIRO, Lêna Vania Ribeiro; BRÄSCHER, Marisa; BURNIER, Sonia. Ciência da Informação: 32 anos (1972-2004) no caminho da história e horizontes de um periódico científico brasileiro. Ciência da Informação, Brasília, v. 34, n. 3, p. 23-75, 
set./dez. 2005. Disponível em: <http://revista.ibict.br/index.php/ciinf/article/view/816>. Acesso em: 23 nov. 2011.

PINHEIRO, Lêna Vania Ribeiro; LOUREIRO, José Mauro Matheus. Traçados e limites da ciência da informação. Ciência da Informação, Brasília, v. 24, n. 1, p. 4253, jan./abr. 1995. Disponível em:

<http://revista.ibict.br/index.php/ciinf/article/view/531>. Acesso em: 23 nov. 2011.

ROBREDO, Jaime. Da ciência da informação revisitada aos sistemas humanos de informação. Brasília: Thesaurus, 2003.

SARACEVIC, Tefko. Ciência da informação: origem, evolução e relações.

Perspectivas em Ciência da Informação, Belo Horizonte, v. 1, n. 1, 1996. Disponível em: <http://portaldeperiodicos.eci.ufmg.br/index.php/pci/article/view/235 >. Acesso em: 23 nov. 2011.

SMITH, J. H.; TALÁMO, M. F. G. M.; KOBASHI, N. Y. A determinação do campo científico da ciência da informação: uma abordagem terminológica. DataGramaZero, [S.I.], v. 5, n. 1, fev. 2004. Disponível em: <http://www.dgz.org.br/fev04/Art_03.htm>. Acesso em: 25 out. 2011.

SOBRE a Revista. Disponível em: <http://revista.ibict.br/index.php/ciinf/about>. Acesso em: 23 nov. 2011.

WEITZEL, Simone Rocha. Fluxo da informação científica. In: POBLACION, D. A.; WITTER, G. P.; SILVA, J. F. M. Comunicação e produção científica: contexto, indicadores e avaliação. São Paulo: Angellara, 2006.

ZAHER, Célia Ribeiro Editorial: IBICT: Perfil de seus primórdios. Ciência da informação, Brasília, v. 34, n. 2, 2005. Disponível em:

<http://revista.ibict.br/index.php/ciinf/article/ view/822/660>. Acesso em: 23 nov. 2011. 